\title{
Active Vibration Reduction of the Advanced Stirling Convertor
}

Scott D. Wilson, Jonathan F. Metscher, and Nicholas A. Schifer

Glenn Research Center, Cleveland, Ohio 


\section{NASA STI Program . . . in Profile}

Since its founding, NASA has been dedicated to the advancement of aeronautics and space science. The NASA Scientific and Technical Information (STI) Program plays a key part in helping NASA maintain this important role.

The NASA STI Program operates under the auspices of the Agency Chief Information Officer. It collects, organizes, provides for archiving, and disseminates NASA's STI. The NASA STI Program provides access to the NASA Technical Report Server-Registered (NTRS Reg) and NASA Technical Report ServerPublic (NTRS) thus providing one of the largest collections of aeronautical and space science STI in the world. Results are published in both non-NASA channels and by NASA in the NASA STI Report Series, which includes the following report types:

- TECHNICAL PUBLICATION. Reports of completed research or a major significant phase of research that present the results of NASA programs and include extensive data or theoretical analysis. Includes compilations of significant scientific and technical data and information deemed to be of continuing reference value. NASA counter-part of peer-reviewed formal professional papers, but has less stringent limitations on manuscript length and extent of graphic presentations.

- TECHNICAL MEMORANDUM. Scientific and technical findings that are preliminary or of specialized interest, e.g., "quick-release" reports, working papers, and bibliographies that contain minimal annotation. Does not contain extensive analysis.
- CONTRACTOR REPORT. Scientific and technical findings by NASA-sponsored contractors and grantees.

- CONFERENCE PUBLICATION. Collected papers from scientific and technical conferences, symposia, seminars, or other meetings sponsored or co-sponsored by NASA.

- SPECIAL PUBLICATION. Scientific, technical, or historical information from NASA programs, projects, and missions, often concerned with subjects having substantial public interest.

- TECHNICAL TRANSLATION. Englishlanguage translations of foreign scientific and technical material pertinent to NASA's mission.

For more information about the NASA STI program, see the following:

- Access the NASA STI program home page at http://www.sti.nasa.gov

- E-mail your question to help@sti.nasa.gov

- $\quad$ Fax your question to the NASA STI Information Desk at 757-864-6500

- Telephone the NASA STI Information Desk at 757-864-9658

- Write to:

NASA STI Program

Mail Stop 148

NASA Langley Research Center Hampton, VA 23681-2199 
NASA/TM-2016-219416

\section{Active Vibration Reduction of the Advanced Stirling Convertor}

Scott D. Wilson, Jonathan F. Metscher, and Nicholas A. Schifer

Glenn Research Center, Cleveland, Ohio

Prepared for the

14th International Energy Conversion Engineering Conference (IECEC)

sponsored by AIAA

Salt Lake City, Utah, July 25-27, 2016

National Aeronautics and

Space Administration

Glenn Research Center

Cleveland, Ohio 44135 


\section{Acknowledgments}

This work is funded through the NASA Science Mission Directorate and the Radioisotope Power Systems Program Office. The authors wish to acknowledge Mike Brace and Wayne Gerber for their commitments and contributions to Stirling technology research.

This report is a formal draft or working paper, intended to solicit comments and ideas from a technical peer group.

This report contains preliminary findings, subject to revision as analysis proceeds.

Trade names and trademarks are used in this report for identification only. Their usage does not constitute an official endorsement, either expressed or implied, by the National Aeronautics and Space Administration.

Level of Review: This material has been technically reviewed by technical management.

Available from

NASA STI Program

Mail Stop 148

NASA Langley Research Center

Hampton, VA 23681-2199
National Technical Information Service 5285 Port Royal Road Springfield, VA 22161 703-605-6000

This report is available in electronic form at http://www.sti.nasa.gov/ and http://ntrs.nasa.gov/ 


\title{
Active Vibration Reduction of the Advanced Stirling Convertor
}

\author{
Scott D. Wilson, Jonathan F. Metscher, and Nicholas A. Schifer \\ National Aeronautics and Space Administration \\ Glenn Research Center \\ Cleveland, Ohio 44135
}

\begin{abstract}
Stirling Radioisotope Power Systems (RPS) are being developed as an option to provide power on future space science missions where robotic spacecraft will orbit, flyby, land or rove. A Stirling Radioisotope Generator (SRG) could offer space missions a more efficient power system that uses one fourth of the nuclear fuel and decreases the thermal footprint compared to the current state of the art. The Stirling Cycle Technology Development (SCTD) Project is funded by the RPS Program to developing Stirling-based subsystems, including convertors and controller maturation efforts that have resulted in high fidelity hardware like the Advanced Stirling Radioisotope Generator (ASRG), Advanced Stirling Convertor (ASC), and ASC Controller Unit (ACU). The SCTD Project also performs research to develop less mature technologies with a wide variety of objectives, including increasing temperature capability to enable new environments, improving system reliability or fault tolerance, reducing mass or size, and developing advanced concepts that are mission enabling. Active vibration reduction systems (AVRS), or "balancers", have historically been developed and characterized to provide fault tolerance for generator designs that incorporate dual-opposed Stirling convertors or enable single convertor, or small RPS, missions. Balancers reduce the dynamic disturbance forces created by the power piston and displacer internal moving components of a single operating convertor to meet spacecraft requirements for induced disturbance force. To improve fault tolerance for dual-opposed configurations and enable single convertor configurations, a breadboard AVRS was implemented on the Advanced Stirling Convertor (ASC). The AVRS included a linear motor, a motor mount, and a closed-loop controller able to balance out the transmitted peak dynamic disturbance using acceleration feedback. Test objectives included quantifying power and mass penalty and reduction in transmitted force over a range of ASC operating parameters and mounting conditions. All tests were performed at three different piston amplitudes, 3.0, 3.75, and $4.5 \mathrm{~mm}$. Overall, the transmitted force was reduced to 2 percent of the total unbalanced force by actively balancing out only the first fundamental frequency, with balancer motor power remaining under 1 watt. The test results will be used to guide future balancer designs.
\end{abstract}

\section{Nomenclature}

$\begin{array}{ll}\text { ACU } & \text { ASC Controller Unit } \\ \text { ASC }(-E) & \text { Advanced Stirling Convertor (Engineering design \#1) } \\ (- \text { E2 }) & \text { Engineering design \#2 } \\ (- \text { E3) } & \text { Engineering design \#3 } \\ (- \text { F }) & \text { Fight design } \\ \text { ASRG } & \text { Advanced Stirling Radioisotope Generator } \\ \text { AVRS } & \text { Active Vibration Reduction System } \\ \text { CONOPS } & \text { Concept of Operations } \\ \text { Acmd } & \text { Convertor Command Voltage } \\ \text { DCC } & \text { Dual Convertor Controller } \\ \text { DOE } & \text { Department of Energy } \\ \text { GHA } & \text { Generator Housing Assembly } \\ \text { GPHS } & \text { General Purpose Heat Source } \\ \text { GRC } & \text { Glenn Research Center }\end{array}$




$\begin{array}{ll}\text { LMS } & \text { Least Mean Squares } \\ \text { LMSSC } & \text { Lockheed Martin Space Systems Company } \\ \text { RPS } & \text { Radioisotope Power Systems } \\ \text { SRG } & \text { Stirling Radioisotope Generator } \\ \text { SCTD } & \text { Stirling Cycle Technology Development } \\ \text { TRL } & \text { Technology Readiness Level }\end{array}$

\section{Stirling Cycle Technology Development Project}

Stirling Radioisotope Power Systems (RPS) are being developed by NASA's RPS Program in collaboration with the U.S. Department of Energy (DOE). SRGs could provide power to future space science missions where robotic spacecraft will orbit, flyby, land or rove. The Stirling Cycle Technology Development (SCTD) Project is funded by the RPS Program to developing Stirling-based subsystems, including convertors and controller maturation efforts that have resulted in high fidelity hardware like the Advanced Stirling Radioisotope Generator (ASRG), Advanced Stirling Convertor (ASC), and ASC Controller Unit (ACU) (Refs. 1 and 2). The SCTD Project also performs research to develop less mature technologies with a wide variety of objectives, including increasing temperature capability to enable new environments, improving system reliability or fault tolerance, reducing mass or size, and developing advanced concepts that are mission enabling (Ref. 3). Active vibration reduction systems have historically been developed and characterized to provide fault tolerance for generator designs that incorporate dualopposed Stirling convertors or single convertors (Refs. 4 and 5). To improve fault tolerance of an ASRGlike configuration or enable a single convertor generator design, an Active Vibration Reduction System (AVRS) has been demonstrated using an ASC in a laboratory environment.

The ASRG major subsystems included two ASC, two General Purpose Heat Sources (GPHS), one ACU, and a generator housing assembly (GHA). Figure 1 shows two convertors arranged in a dual-opposed configuration, similar to the ASRG design. This interconnect cylinder shown is a non-flight design used to mount the balancer linear motor between two convertors. Made from relatively inexpensive material without consideration of flight loads or mass goals, it was designed to enable laboratory tests by adapting a balancer to a variety of ASC designs in single or dual-opposed configurations.

The purpose of this test effort was to characterize the AVRS operating with a single Advanced Stirling Convertor (ASC) convertor. High-level project goals include evaluation of system integration for mechanical design and control methods, characterizing performance of a single convertor against potential mission conditions, and demonstration of active vibration reduction to adequate levels for a single ASC. For reference, the ASRG specification required a maximum peak dynamic disturbance force transmitted to the space vehicle to less than $35 \mathrm{~N}$ when both ASCs are operating. While past testing of dual-opposed ASC, which provides canceling dynamic forces, has resulted in a much lower disturbance force than the ASRG requirement, testing with the AVRS show that requirement is easily met with a single convertor.

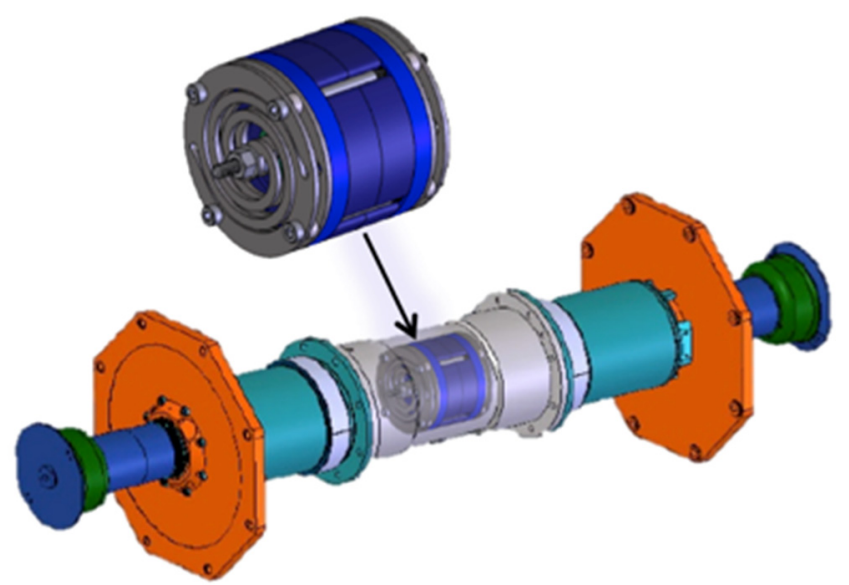

Figure 1.-Stirling convertors in dual-opposed configuration with balancer mounted inside a modified version of the interconnect cylinder. 
The AVRS was developed by Sunpower, Inc. under contract to GRC. The AVRS design is based on an active balancing system produced by Sunpower, Inc. for their commercial CryoTel cryocooler product line. That CryoTel active balancing system was originally adapted from technology first developed by Sunpower, Inc. under NASA contract NNC09TA29T, which produced two applicable patents: United States Patent 8800302 and 8860381 . The AVRS controller box includes control authority for the balancer linear motor as well as the ASC linear alternator. The balancer linear motor was also revised to enable a reduction in force up to $450 \mathrm{~N}$ at a piston amplitude of $4.5 \mathrm{~mm}$.

\section{Test Hardware}

This characterization test used an active vibration reduction system mounted to ASC-E2 \#6. The convertor was designed to produce a nominal $80 \mathrm{We}$ from $250 \mathrm{Wth}$ gross heat input and utilizes a nickelbased super alloy heater head to enable a maximum hot-end temperature of $850^{\circ} \mathrm{C}$. It has been designed for a rejection temperature range of 4 to $121{ }^{\circ} \mathrm{C}$ and an alternator housing temperature range of 11 to $130{ }^{\circ} \mathrm{C}$. This convertor has been hermetically sealed by welding the pressure joints, filling with high purity helium, and welding the fill tube closure. ASC-E2 \#6 was rebuilt in 2015 to be more like an ASC-E3, including revisions to the gas bearing system and alternator.

While the hardware fidelity of the balancer linear motor is closer to a scaled brassboard, the balancer controller has been integrated into a non-flight design controller box which also provides control authority for the ASC. Due to cost and schedule considerations for this initial characterization on a single convertor, the decision was made to pursue a less costly balancer controller design only able to balance the first fundamental frequency of an operating ASC. Modifications to the balancer controller design could include higher harmonic balancing and control authority for two ASC, enabling simulation of one failed convertor. Figure 2 shows the balancer linear motor, the interconnect cylinder used to mount the balancer linear motor to a single convertor, and the controller box that provides control authority for a single ASC and balancer linear motor. The interconnect cylinder was not designed to be light weight or representative of flight designs. Instead, it was designed to mount the balancer linear motor to a single convertor or to a dualopposed pair of convertors. It allows for about $5 \mathrm{~mm}$ of clearance between the convertor pressure vessel and mover rod located on the linear motor, at a convertor piston amplitude of $4.5 \mathrm{~mm}$. For flexibility, it is also able to adapt to hermetic and non-hermetic ASC designs. The mass of the assembly, containing the interconnect cylinder and linear motor, is 1535 grams while the mass of the linear motor is only around 900 grams. Many design changes can be made to reduce the 635 gram interconnect cylinder but the linear motor design is considered to be high fidelity so the mass cannot be significantly reduced for use with ASCs.

The balancer controller uses a closed-loop active feedback signal supplied by a PCD Piezotronics $352 \mathrm{C} 66$ accelerometer. The accelerometer feedback signal is amplified, low-pass filtered, and converted to a digital signal before being passed to the harmonic signal generators. Each signal generator uses a Least Mean Squares (LMS) adaptive filter algorithm to determine the error signal based on the accelerometer feedback signal and the feed-forward convertor command voltage (Acmd). The feed-forward Acmd signal acts as a proportional gain and determines the amplitude of the balancing signal generated. The output from the LMS algorithm gives a balancing signal for a particular harmonic frequency assigned based on the feedback accelerometer. The balancing signal from each harmonic signal generator is then summed and

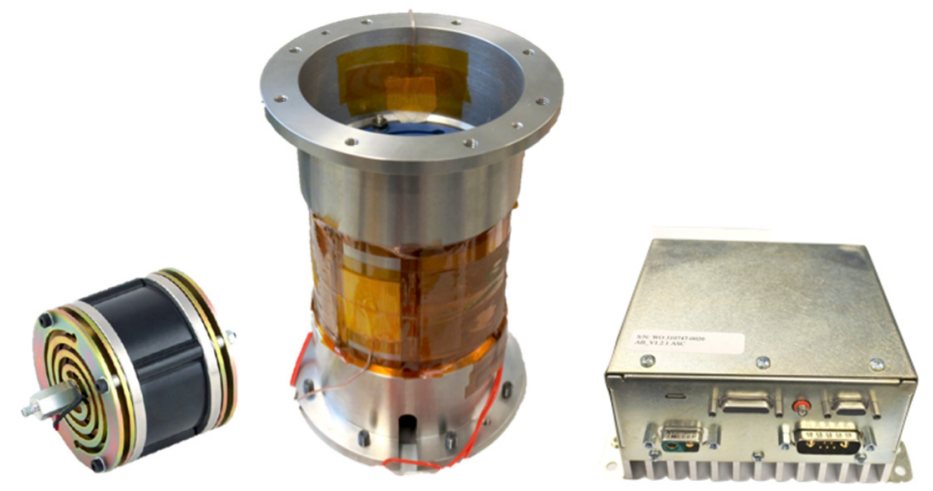

Figure 2.-Balancer linear motor (left), interconnect cylinder (center), and controller box providing control authority for ASC and balancer linear motor (right). 
output by pulse width modulation. In this test, only the first signal generator (first fundamental frequency) was used. Based on Test 2.5, the accelerometer feedback seems to play a smaller role compared to the proportional gain determined by the Acmd signal.

The ASC was oriented heater head down to enable measurement of transmitted force through load cells mounted between mounting rods and an adapter plate. The adapter plate was mounted on two different base plate configurations, explained in more detail later. The process of starting an ASC in heater head down orientation can be constrained by time if the piston freely drifts toward the heater head, coming in contact with the displacer before the piston gas bearings can be charged and centered. To enable a repeatable and low risk process for starting with the heater head facing down, an auto-centering circuit was developed by Mike Brace of GRC and implemented with the Sunpower ASC controller. This implementation successfully demonstrated the first-time use of an auto-centering circuit on an ASC with the heater head facing down while under the control authority of a digital controller. The test control rack contained a LabVIEW graphical user interface to enable user input commands directly to the Sunpower controller, such as the command voltage set point. The test setup measured force using (4x) Kistler 9251A-Fx (0 to $550 \mathrm{lbs}),(3 \mathrm{x})$ 107B 4-gang connector, (3x) 5010 Dual Mode Amps. It also measured a reference acceleration, separate from the feedback to the balancer controller but in the same location, using a Kistler Type 8692C. This reference acceleration is reported here.

To complete the setup process after all hardware has been installed and connected, an initialization routine is performed to store structural response coefficients into the memory of the balancer controller. This initialization routine is performed any time changes are made to the convertor mounting design or if the feedback accelerometer is moved. After setup is complete, the user sends a commanded voltage for the convertor. During startup or transition to any other commended voltage set point, the controller uses a hardcoded slew rate of $4 \mathrm{Vrms} / \mathrm{sec}$ to avoid drive motor current spikes.

Figure 3 shows the balancer test setup, where the ASC is oriented with the heater head down and alternator up. Two separate mounting configurations were used to meet objective 1 . The soft mounting configuration fixed the mount plate to a $150 \mathrm{lbs}$ mass, suspended on top of four relatively soft springs (38 lbf/in spring stiffness). The floating mass is able to isolate the force generated by the convertor's oscillating piston by dynamically responding a fraction of the piston amplitude. The rigid mounting configuration fixed the mount plate to a several hundred pound table. The table was originally mounted to the floor using floor anchors. However, the floor anchors were faulty so the table legs were set onto a thin layer of rubber, achieving 97 percent of the peak disturbance transmitted load experienced when fixed to ground.

\section{Objectives and Test Matrix}

High-level project goals include evaluation of system integration for mechanical design and control methods, characterizing performance of AVRS on a single convertor across a range of temperatures and piston amplitudes, and demonstration of active vibration reduction to adequate levels for a single ASC. To achieve these goals, specific objectives were used to formulate a test matrix which contained all of the desired parameter variations. The test objectives are: 1) quantify induced force while under control of Active Vibration Reduction System (AVRS) for rigid and soft mounting conditions, 2) quantify power consumed by balancer linear motor for all tests, quantify additional balancer mass penalty, 3) quantify reduction in force while under control of AVRS

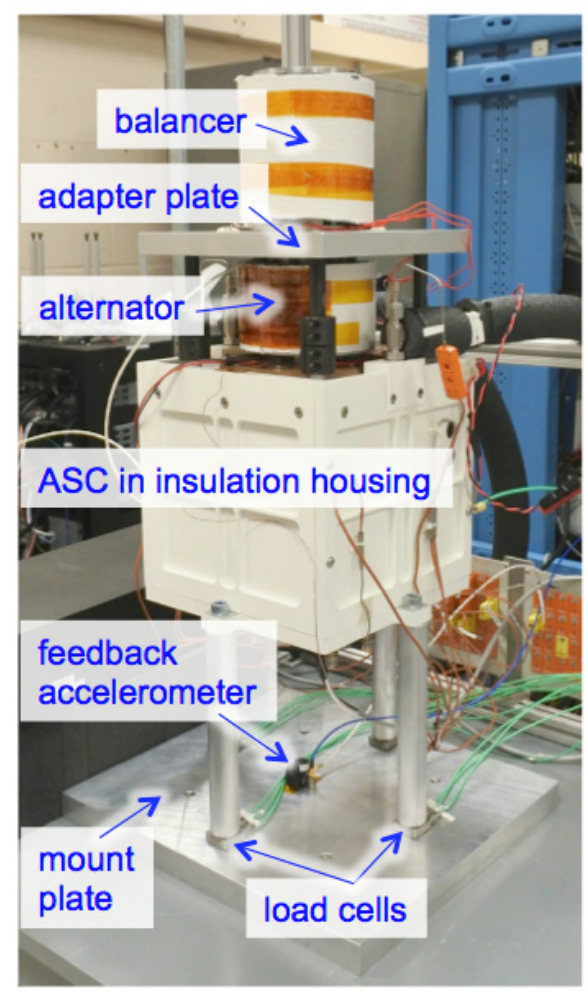

Figure 3.-Balancer test setup. 
compared to passive vibration reduction and no vibration reduction, 4) quantify induced force while under control of AVRS for varying temperatures, 5) quantify induced force while under control of AVRS for varying feedback accelerometer location, and 6) pathfind test processes and rack configurations for a single ASC configuration and provide test data for model validation. The test objectives compared the transmitted peak disturbance force from the ASC with no motor attached (unbalanced), with the motor attached but electrically deactivated (passively balanced), and with the motor attached and activated (actively balanced). ASC Rejection and Alternator Housing Temperature were varied from 38 to $90{ }^{\circ} \mathrm{C}$ and 46 to $98{ }^{\circ} \mathrm{C}$, respectively. The interconnect cylinder was outfitted with film heaters in order to vary the balancer temperature from 46 to $98^{\circ} \mathrm{C}$, to quantify temperature effect on balancer performance independently of cold-end temperatures. Finally, the location of the feedback accelerometer was varied between two locations. The "in-line" location was aligned along the convertor axis and fixed to the mounting plate near the load cells. The "off-axis" location was $40 \mathrm{~mm}$ off convertor axis and fixed to the top edge of the interconnect cylinder, about $150 \mathrm{~mm}$ above the ASC alternator housing flange. This "off-axis" location is significant because it is as far from the load cells as possible in this test setup.

Table 1 shows the tested configurations and corresponding balancing modes with each test number called out. Tests 1.1 and 1.4 were used to meet Objective 1. All test results were used to meet Objective 2. Tests 1.3, 1.4, and 2.1 were used to meet Objective 3. Tests 1.4, 2.2, 2.3, 2.6, and 2.7 were used to meet Objective 4. Test 1.4 and 2.4 were used to meet Objective 5. Test 2.5 was intended to demonstrate balancer functionality while not operating on the Sunpower controller but rather operating the ASC under authority of an AC Bus power source while the balancer controller was activated. In that test, the balancer linear motor was ultimately only able to reduce the vibration force by about 70 percent, from the passively balanced vibration level of $220 \mathrm{~N}$. This test demonstrated how the controller algorithm uses a feed-forward convertor command voltage signal as a proportional gain to determine the amplitude of the balancing signal generated.

TABLE 1.-TEST CONFIGURATIONS

\begin{tabular}{|c|c|c|c|}
\hline Mode & Active & $\begin{array}{l}\text { Passive } \\
\end{array}$ & None \\
\hline Installation & Balancer installed & Balancer installed & Balancer removed \\
\hline Activation & Activated & Deactivated & $\mathbf{n} / \mathbf{a}$ \\
\hline Soft mount & & Not tested & a \\
\hline \multirow{2}{*}{\multicolumn{4}{|c|}{ Rigid mount }} \\
\hline & & & \\
\hline Tests & $\begin{array}{c}1.4 \\
2.2,2.3 \\
2.4 \\
2.6,2.7\end{array}$ & 2.1 & 1.3 \\
\hline
\end{tabular}

Test 2.5 not shown 


\section{Test Results and Conclusions}

Specific objectives were used to formulate a test matrix and meet the high-level project goals. These objectives are described in more detail along with supporting data. Table 2 summarizes all tests with exception of Test 2.5, summarized briefly in Section III, and Test 2.6, which is summarized later in this section. The test parameters shown are acceptor temperature, rejector temperature, balancer temperature, and piston amplitude. The piston amplitude is proportional to a controller command voltage which is not shown. Each test resulted in a measured load, summed from signals measured in three orthogonal axis, near-axial acceleration which is recorded just next to the centrally aligned controller feedback accelerometer, and balancer linear motor current, voltage, and power input. The values "N/A" are shown in Tests 1.2 and 1.3 because the balancer was not installed. Similarly, there are "N/A" values shown in Test 2.1 because the balancer was installed but was not electrically connected, or not activated. The acceptor temperature was maintained at $760{ }^{\circ} \mathrm{C}$ for all tests, while rejector and alternator housing temperatures were varied to achieve beginning of mission (BOM) low reject (-LR) and high reject (-HR) conditions, as specified in the ASRG specification. The external surface of the interconnect cylinder was outfitted with film heaters in order to vary the temperature of the balancer linear motor, mounted inside the cylinder. The balancer temperature was approximated using a temperature reading close to, but not directly on, the linear motor. All tests were operated at three piston amplitude values $(3.0,3.75$, and $4.5 \mathrm{~mm})$.

TABLE 2.-SUMMARY OF TEST RESULTS

[5 min. averaged data.]

\begin{tabular}{|c|c|c|c|c|c|c|c|c|c|c|c|c|c|c|c|c|}
\hline \multirow{2}{*}{\begin{tabular}{|l|} 
Test Point \\
1.1 .1 \\
\end{tabular}} & \multirow{4}{*}{$\begin{array}{c}\text { Test Description } \\
\text { Active-Soft } \\
\text { In-line feedback }\end{array}$} & \multirow{2}{*}{\begin{tabular}{|c|}
$\begin{array}{c}\text { Acceptor Temp } \\
\left({ }^{\circ} \mathrm{C}\right)\end{array}$ \\
758.59 \\
\end{tabular}} & \multicolumn{2}{|c|}{$\begin{array}{c}\text { Rejector Temp } \\
\left({ }^{\circ} \mathrm{C}\right)\end{array}$} & $\begin{array}{l}\text { Alt. Housing } \\
\text { Temp }\left({ }^{\circ} \mathrm{C}\right)\end{array}$ & $\begin{array}{c}\text { Balancer Temp } \\
\left({ }^{\circ} \mathrm{C}\right)\end{array}$ & $\begin{array}{l}\text { Piston Amp. } \\
\text { (mm) }\end{array}$ & \multirow{2}{*}{\begin{tabular}{r|}
$Z$ L Load $(N)$ \\
6.94
\end{tabular}} & \multicolumn{2}{|c|}{$\begin{array}{c}\text { Axial } \\
\text { Acceleration (g) }\end{array}$} & \multicolumn{2}{|c|}{$\begin{array}{c}\text { Balancer } \\
\text { Current (Arms) }\end{array}$} & \multicolumn{2}{|c|}{\begin{tabular}{|c|} 
Balancer \\
Voltage (Vrms)
\end{tabular}} & \multicolumn{2}{|c|}{\begin{tabular}{|c|} 
Balancer Power \\
(W)
\end{tabular}} \\
\hline & & & \begin{tabular}{|l|l}
$\square$ \\
\end{tabular} & 38.14 & 45.43 & \begin{tabular}{|r|}
45.64 \\
\end{tabular} & $\square \quad 3.03$ & & & 0.022 & $\square$ & 0.13 & 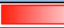 & 4.64 & $\square$ & 0.27 \\
\hline 1.1 .2 & & 758.58 & 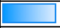 & 38.55 & 46.06 & 45.00 & 3.75 & 9.04 & & 0.024 & $\square$ & 0.16 & & 5.82 & $\square$ & 0.44 \\
\hline 1.1 .3 & & 759.38 & 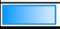 & 38.70 & 44.69 & 44.55 & 4.52 & 12.93 & & 0.032 & 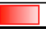 & 0.19 & & 7.15 & 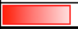 & 0.70 \\
\hline 1.2 .1 & \multirow{3}{*}{$\frac{\text { Removed - Soft }}{\text { no feedback }}$} & 758.93 & ב & 37.79 & 45.25 & $\mathrm{~N} / \mathrm{A}$ & 3.04 & 154.87 & & 0.277 & $\mathrm{~N} / \mathrm{A}$ & & $\mathrm{N} / \mathrm{A}$ & & $\mathrm{N} / \mathrm{A}$ & \\
\hline 1.2 .2 & & 758.12 & 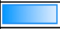 & 39.54 & 44.63 & $\mathrm{~N} / \mathrm{A}$ & 3.73 & 192.03 & & 0.337 & $\mathrm{~N} / \mathrm{A}$ & & $\mathrm{N} / \mathrm{A}$ & & $\mathrm{N} / \mathrm{A}$ & \\
\hline 1.2 .3 & & 759.76 & 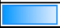 & 39.06 & 45.21 & $\mathrm{~N} / \mathrm{A}$ & 4.50 & 232.52 & & 0.406 & $\mathrm{~N} / \mathrm{A}$ & & $\mathrm{N} / \mathrm{A}$ & & $\mathrm{N} / \mathrm{A}$ & \\
\hline 1.3.1 & \multirow{3}{*}{$\begin{array}{c}\text { Removed - Rigid } \\
\text { no feed back }\end{array}$} & 759.89 & $\square$ & 38.25 & 45.24 & $\mathrm{~N} / \mathrm{A}$ & 3.03 & 216.59 & & 0.087 & $\mathrm{~N} / \mathrm{A}$ & & $\mathrm{N} / \mathrm{A}$ & & $\mathrm{N} / \mathrm{A}$ & \\
\hline 1.3 .2 & & 758.82 & 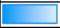 & 38.77 & 45.51 & $\mathrm{~N} / \mathrm{A}$ & 3.76 & 270.41 & & 0.116 & $\mathrm{~N} / \mathrm{A}$ & & $\mathrm{N} / \mathrm{A}$ & & $\mathrm{N} / \mathrm{A}$ & \\
\hline \begin{tabular}{l|l|}
1.3 .3 \\
\end{tabular} & & 758.60 & e & 39.59 & 45.32 & $\mathrm{~N} / \mathrm{A}$ & 4.48 & 323.28 & & 0.149 & $\mathrm{~N} / \mathrm{A}$ & & $\mathrm{N} / \mathrm{A}$ & & $\mathrm{N} / \mathrm{A}$ & \\
\hline 1.4 .1 & \multirow{3}{*}{$\frac{\text { Active- Rigid }}{\text { In-line feedback }}$} & 759.34 & $\overline{\mathrm{z}}$ & 38.61 & 45.23 & 46.61 & 2.99 & 5.38 & & 0.050 & $\square$ & 0.13 & & 4.53 & $\square$ & 0.26 \\
\hline 1.4 .2 & & 758.79 & 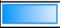 & 38.91 & 444.69 & 45.47 & 3.75 & 5.26 & & 0.078 & $\square$ & 0.17 & & 5.85 & \begin{tabular}{|l|l}
$\square$ \\
$\square$
\end{tabular} & 0.45 \\
\hline 1.4 .3 & & 759.25 & 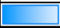 & 39.94 & 45.41 & 45.25 & 4.51 & 6.69 & & 0.115 & 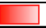 & 0.19 & & 7.19 & 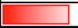 & 0.69 \\
\hline 2.1 .1 & \multirow{3}{*}{$\frac{\text { Passive - Rigid }}{\text { no feedback }}$} & 759.43 & $\square$ & 39.28 & 45.20 & 45.91 & 3.00 & 136.73 & & 0.059 & $\mathrm{~N} / \mathrm{A}$ & & $\mathrm{N} / \mathrm{A}$ & & $\mathrm{N} / \mathrm{A}$ & \\
\hline 2.1 .2 & & 759.03 & 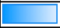 & 39.14 & 444.56 & 46.18 & 3.76 & 177.53 & & 0.086 & $\mathrm{~N} / \mathrm{A}$ & & $\mathrm{N} / \mathrm{A}$ & & N/A & \\
\hline 2.1 .3 & & 758.26 & 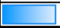 & 38.29 & 45.28 & 46.80 & 4.52 & 220.36 & & 0.122 & $\mathrm{~N} / \mathrm{A}$ & & $\mathrm{N} / \mathrm{A}$ & & N/A & \\
\hline 2.2 .1 & \multirow{3}{*}{$\frac{\text { Active- Rigid }}{\text { In-line feedback }}$} & 759.99 & & 89.02 & 97.69 & 98.72 & 3.02 & 10.77 & & 0.051 & & 0.43 & $\square$ & 1.85 & \begin{tabular}{|l|l}
$\square$ \\
\end{tabular} & 0.54 \\
\hline 2.2 .2 & & 759.48 & & 89.48 & 97.20 & 98.63 & 3.73 & 10.62 & & 0.074 & & 0.52 & $\square$ & 2.39 & $\square$ & 0.85 \\
\hline 2.2 .3 & & 758.57 & & 90.49 & 96.60 & 98.87 & 4.51 & 9.91 & & 0.114 & & 0.63 & 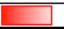 & 3.08 & & 1.31 \\
\hline \multirow{3}{*}{\begin{tabular}{|l|}
2.3 .1 \\
2.3 .2 \\
2.3 .3 \\
\end{tabular}} & \multirow{3}{*}{$\frac{\text { Active-Rigid }}{\text { In-line feedback }}$} & 759.36 & $\square$ & 38.78 & 45.43 & 97.98 & 2.99 & 8.47 & & 0.052 & & 0.38 & $\square$ & 2.03 & \begin{tabular}{|l|l}
$\square$ \\
\end{tabular} & 0.44 \\
\hline & & 758.90 & 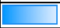 & 39.47 & 46.01 & 97.22 & 3.75 & 7.88 & & 0.081 & 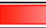 & 0.47 & \begin{tabular}{|l|l|}
$\square$ \\
\end{tabular} & 2.78 & 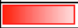 & 0.74 \\
\hline & & 758.89 & 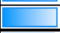 & 39.28 & 47.60 & 97.69 & 4.48 & 8.75 & & 0.120 & & 0.55 & $\square$ & 3.45 & & 1.10 \\
\hline \begin{tabular}{|l|}
2.4 .1 \\
\end{tabular} & \multirow{3}{*}{$\begin{array}{l}\text { Active- Rigid } \\
\text { Off-axis feedback }\end{array}$} & 759.66 & 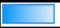 & 37.51 & \begin{tabular}{|l|}
45.45 \\
\end{tabular} & |45.49 & 3.04 & 19.73 & & 0.055 & $\square$ & 0.10 & & 4.61 & $\square$ & 0.23 \\
\hline 2.4 .2 & & 759.05 & 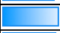 & 39.80 & 45.92 & 45.64 & 3.76 & 16.80 & & 0.083 & $\square$ & 0.13 & 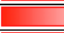 & 5.97 & 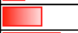 & 0.40 \\
\hline 2.4 .3 & & 759.82 & 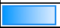 & 38.41 & 46.49 & 45.58 & 4.48 & 18.05 & & 0.123 & 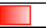 & 0.15 & & 7.25 & & 0.60 \\
\hline 2.7.1 & \multirow{3}{*}{$\begin{array}{c}\text { Active- Rigid } \\
\text { In-line feedback } \\
46^{\circ} \mathrm{C} \text { initialization }\end{array}$} & 760.47 & 0 & 37.81 & 45.34 & 46.44 & 3.04 & 5.86 & & 0.056 & $\square$ & 0.11 & & 4.91 & $\square$ & 0.27 \\
\hline 2.7 .2 & & 760.08 & t & 38.54 & 44.76 & 45.75 & 3.76 & 6.17 & & 0.084 & $\square$ & 0.14 & & 6.26 & \begin{tabular}{|l|} 
\\
\end{tabular} & 0.45 \\
\hline 2.7 .3 & & 759.45 & & 38.86 & 46.57 & 45.50 & 4.48 & 8.05 & & 0.123 & $\square$ & 0.16 & & 7.64 & & 0.67 \\
\hline
\end{tabular}

Tests 2.5 and 2.6 not shown 


\section{A. Objective 1: Quantify induced force for rigid and soft mounting conditions}

To quantify induced force while under control of Active Vibration Reduction System (AVRS) for rigid and soft mounting conditions, two separate mounting configurations were used. While it is acknowledged the soft mounting configuration looks dynamically less like a spacecraft mount compared to the rigid configuration, these two mounting configurations allowed characterization across two extreme cases. Figure 4 shows the disturbance force plotted against piston amplitude, for BOM-LR temperatures. Tests 1.1 and 1.4 represent active balancing on the soft and rigid mount, respectively. Tests 1.2 and 1.3 represent unbalanced conditions on the soft and rigid mount, respectively. The soft mount resulted in a lower disturbance force while unbalanced and a higher disturbance force during active balancing. While the disturbance force was close, the measured acceleration was between $2 \mathrm{x}$ and $4 \mathrm{x}$ times higher for the rigid mount, as seen in Table 2. Although the soft mount was able to reduce the disturbance force from $233 \mathrm{~N}$ to $13 \mathrm{~N}$ (95 percent), the rigid configuration reduced the disturbance force from $323 \mathrm{~N}$ to $7 \mathrm{~N}$ (98 percent). These results were used as a basis for continuing the remaining tests using the rigid mounted configuration, based on the desire to maximize the reduction in force during the characterization effort.

\section{B. Objective 2: Quantify power and mass penalty}

Balancer power consumption and disturbance force has been plotted against piston amplitude in Figure 5. Test 1.1 represents active balancing at BOM-LR temperatures on the soft mount while Test 1.4 represents the same conditions on the rigid mount. Test 2.2 represents active balancing at BOM-HR temperatures on the rigid mount. The power consumed by the balancer motor for both the rigid mount and soft mount configurations are almost identical for a given convertor operating condition, despite a significant difference in the induced force experience at the load cells. In the BOM-HR operating condition, the balancer requires more power due to increased resistance and the change in natural frequency of the motor springs.

The mass penalty should include the balancer linear motor, a small additional mass for the extra interconnect cylinder material needed to accommodate the balancer motor, and the additional electronics required for control and connection. For this study, the balancer motor was a scaled brassboard while all other components are breadboard and not representative of flight designs. The assembly that contains the interconnect cylinder and linear motor was measured to be 1535 grams while the mass of the linear motor 
was estimated to be only 900 grams. The interconnect cylinder design was not designed to be light weight so there are many changes possible to reduce the 635 gram mass.

\section{Objective 3: Quantify reduction in force for active, passive, and no vibration reduction}

Disturbance force and acceleration are plotted against piston amplitude in Figure 6. All of these tests were run at the BOM-LR temperatures on the rigid mount. Test 1.3 represents no balancing, where the interconnect cylinder with balancer motor were removed from the test setup. Test 2.1 represents passive balancing, where the balancer motor was installed in the interconnect cylinder but not electrically connected. Test 1.4 represents active balancing, where the balancer was installed, electrically connected and activated. The resulting disturbance force for the maximum piston amplitude was $323 \mathrm{~N}$, $220 \mathrm{~N}$, and $7 \mathrm{~N}$ for the unbalanced, passively balanced, and actively balanced conditions. The resulting acceleration values scale as expected for each of the balancing methods, although it is noted that the actively balanced acceleration values are higher than anticipated. While vibration levels could be reduced further if additional harmonic frequencies were used in the input to the controller algorithm, the $7 \mathrm{~N}$

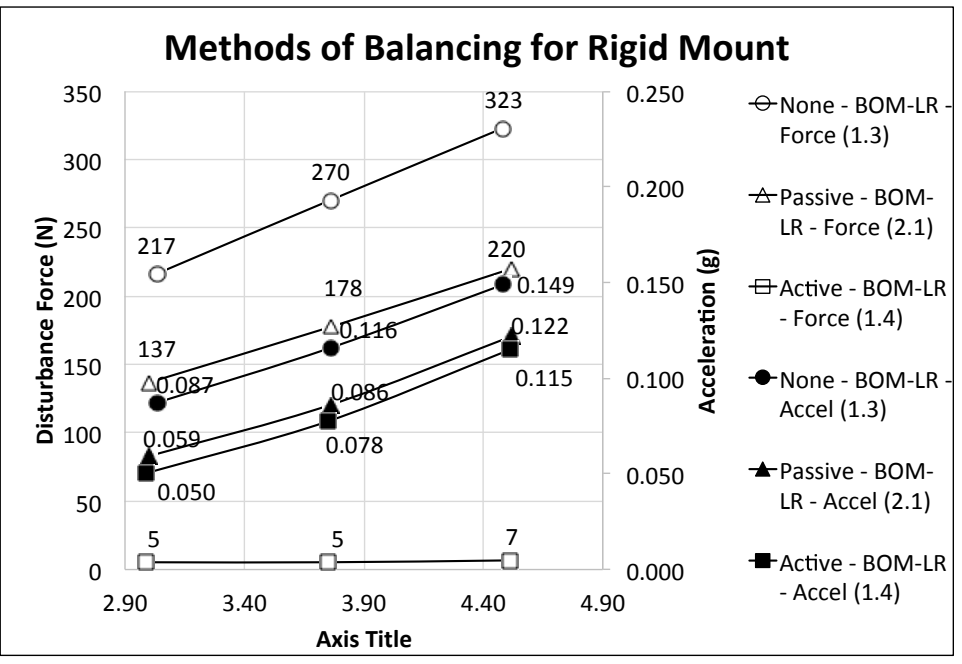

Figure 6.-Methods of Balancing for Tests 1.3, 1.4, and 2.1.

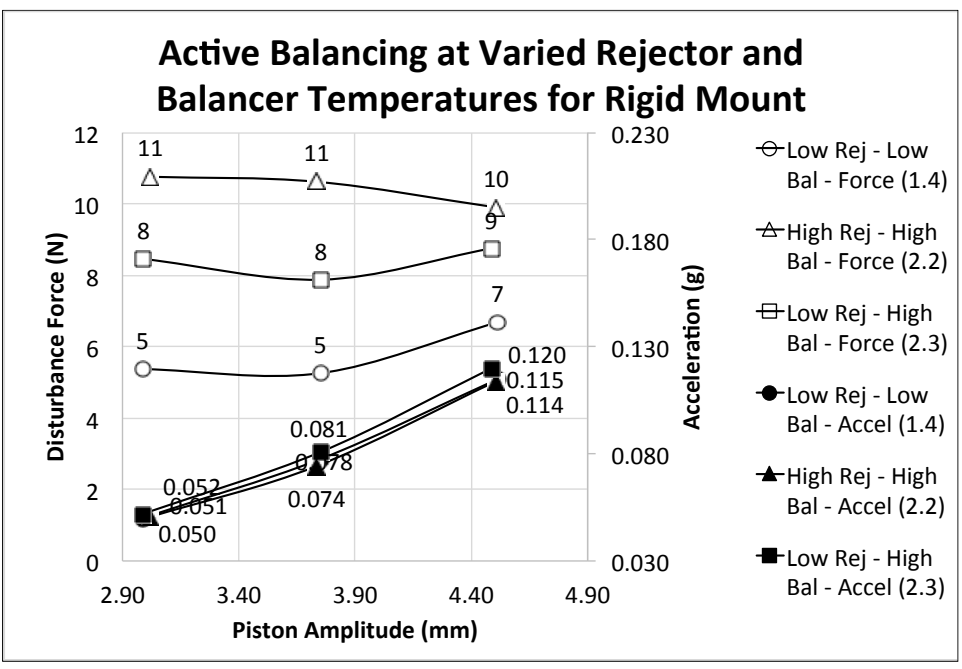

Figure 7.-Temperature Effects for Tests 1.4, 2.2, and 2.3. disturbance force achieved is well below the $35 \mathrm{~N}$ limit imposed by ASRG.

\section{Objective 4: Quantify induced force for varying temperatures}

Tests 1.4, 2.2, 2.3, 2.6, and 2.7 were used to meet Objective 4. The highest amount of power consumed by the balancer was in Test 2.2.3, or active balancing on the rigid mount with in-line feedback for the highest set points for rejector, alternator housing, and balancer temperature. Figure 7 shows the disturbance force and acceleration during Tests 1.4, 2.2, and 2.3. Test 1.4 characterized the performance of the AVRS at a low reject and low balancer temperature. Test 2.2 was conducted with a high reject and high balancer temperature expected during convertor operation at BOM-HR conditions. Results from Test 2.2 show an increase in induced force that trends downward at higher piston amplitude, mostly likely due to the feedforward balancer signal playing a more significant role in balancer algorithm. Further data would be needed to understand the decreasing load signal versus the increasing accelerometer signal. More information on the balancer control algorithm is also needed to quantify the effect of the feed-forward and feedback control gains. Test 2.3 was conducted to decouple the effect of high reject temperature versus high balancer temperature by keeping the balancer temperature high while operating the convertor at the BOM-LR condition. The induced force is lower than in Test 2.2, but higher than in Test 1.4. This indicates that balancer and rejection temperature both play a role in the resultant force. Increased balancer temperature 
reduces the vibration reduction capability of the AVRS, while the increased rejection temperature likely changes the piston/displacer phase angle. This may cause increased vibration forces at higher harmonics while the AVRS will only attempt to reduce vibration at the fundamental frequency. Test 2.6 was added to the original test plan after the significance of the temperature effects was found in Test 2.1.

Test 2.6 repeats the temperature sweep performed on the balancer motor during Test 2.1 but with balancer operating in an active capacity with the AVRS, instead of passively. The convertor was operated in the BOM-LR condition and remained at $3.00 \mathrm{~mm}$ piston amplitude for the entire test. The balancer temperature was increased from room temperature through $75{ }^{\circ} \mathrm{C}$ to explore the effect on axial disturbance force, and acceleration, and balancer power consumption. Figure 8 shows the 2 -second data plot of average balancer temperature, axial disturbance force (Peak Loadcell Z), axial acceleration (Peak Axial Accel), balancer current, balancer voltage, and balancer power consumed. The average axial load does not appear to change significantly over the range of balancer temperatures, but the load cell signal does experience increased noise as the balancer temperature increases. While the balancer current and voltage responded to changes in balancer temperature, the power consumed remained below 0.5 watts.

The balancer initialization procedure must be conducted before operating the convertor with the AVRS. Initialization is typically done while the balancer motor is at ambient conditions. Test 2.7 was intended to determine if an elevated balancer motor temperature achieved during the balancer initialization procedure could affect AVRS algorithm coefficients collected during that process and enable more efficiently performance while at this temperature. The balancer temperature transient, conducted earlier in Test 2.1, indicated that the disturbance force is lowest during passive balancing at a balancer motor temperature of approximately $46^{\circ} \mathrm{C}$.

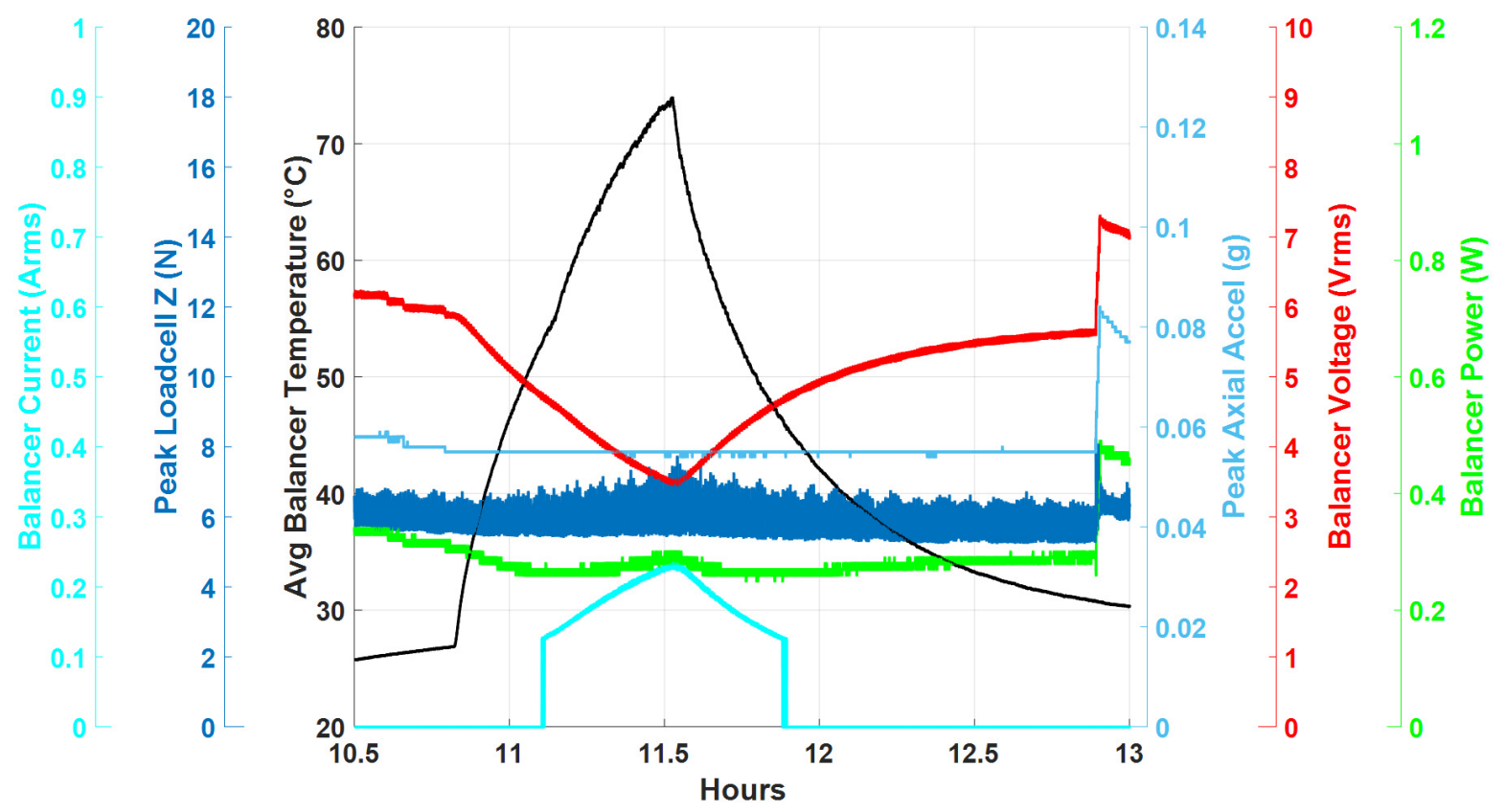

Figure 8.-Balancer Performance During Balancer Temperature Transient in Test 2.6. 
During test 2.7, the initialization procedure was conducted while holding the balancer motor temperature at $46{ }^{\circ} \mathrm{C}$. Figure 9 shows disturbance force and acceleration during Tests 1.4 and 2.7. Unexpectedly, the axial disturbance force was higher for the elevated initialization temperature when compared to results from the test that used an ambient initialization temperature. The cause for this result is being investigated.

\section{E. Objective 5: Quantify induced force for varying feedback accelerometer location}

Test 2.4 was used to meet Objective 5. All previous tests were conducted with the feedback accelerometer located axially in line with the convertor and balancer motor. An axially centered alignment is ideal for maximizing how effective the feedback signal can be to the controller algorithm but that location may not be feasible in spacecraft integration. Test 2.4 was designed to characterize the capability of the AVRS with the feedback accelerometer located in an off-axis position. The initialization process and actively balanced test were conducted on the rigid mount with the feedback accelerometer moved to the mounting flange of the interconnect cylinder, about $40 \mathrm{~mm}$ off-axis and about $150 \mathrm{~mm}$ above the convertor

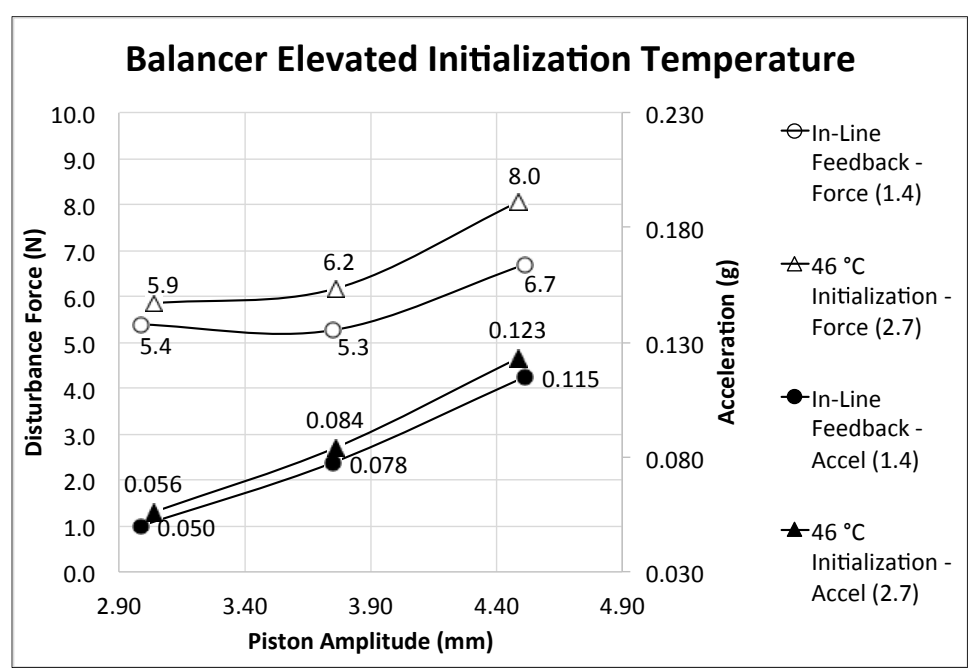

Figure 9.-Higher Temperature Initialization for Tests 1.4 and 2.7.

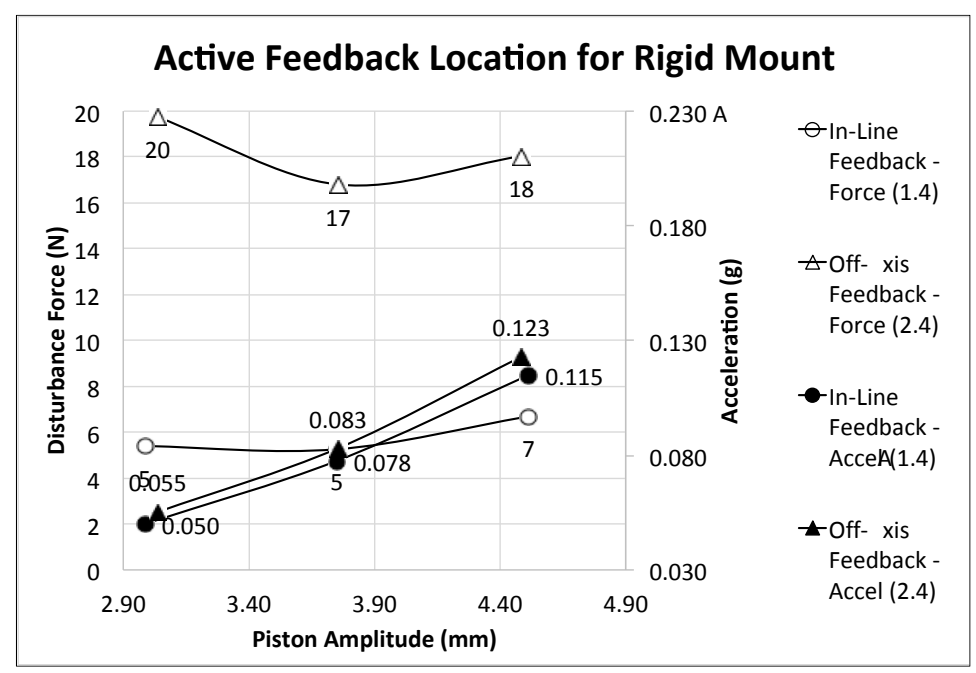

Figure 10.-High Temperature Initialization for Tests 1.4 and 2.4. alternator housing mounting flange. The convertor was operated in the BOM-LR condition at 3.00, 3.75, and $4.50 \mathrm{~mm}$ piston amplitudes to compare to Test 1.4. Figure 10 shows that he resulting disturbance force was $2 x$ higher than when the feedback accelerometer was centrally located. Acceleration was measured using the reference sensor, still located in line with the convertor and not at the off-axis location.

Future work on active vibration reduction systems could include using the test data acquired during this test series to validate models able to predict the dynamic response of the various balancing methods explored here, including unbalanced, passively balanced, and actively balanced. Temperature effects will also be taken into consideration in model validation. The modeling effort is desired to validate the this implementation, including the feed-forward feature of the controller algorithm and attempt to vary the ratio of the convertor command voltage input and the measured acceleration input for optimized dynamic response to various fault conditions. Future implementations could include integration into a high fidelity controller, like the Dual Convertor Controller (DCC) developed by Johns Hopkins University/Applied Physics Laboratory (JHU/APL) and GRC (Ref. 6). Future testing of active vibration reduction systems could include active balancing during random vibration to characterize reduction in excursions of piston amplitude, normally caused by case motion during random vibration testing. 


\section{Conclusion}

The SCTD Project performs research to develop less mature technologies with a wide variety of objectives, including increasing temperature capability to enable new environments, improving system reliability or fault tolerance, reducing mass or size, and developing advanced concepts that are mission enabling. To improve fault tolerance of an ASRG-like configuration or enable a single convertor generator design, an active vibration reduction system was demonstrated using an ASC in a laboratory environment. Test objectives included quantifying power and mass penalty and reduction in transmitted force over a range of ASC operating parameters and mounting conditions. All tests were performed at three different piston amplitudes, 3.0, 3.75, and $4.5 \mathrm{~mm}$. Overall, the transmitted force was reduced 98 percent with balancer motor power remaining under 1 watt. The test results will be used to guide future designs.

\section{References}

1. Lewandowski, E.J. and Oriti, S.M., "Characterization of the Advanced Stirling Radioisotope Generator EU2," Proceedings of the Thirteenth International Energy Conversion Engineering Conference, AIAA, Orlando, FL, 2015.

2. Wong, W.A., Wilson, S.D., Collins, J., Wilson, K., "Advanced Stirling Convertor (ASC) Technology Maturation," Proceedings of the Thirteenth International Energy Conversion Engineering Conference, AIAA, Orlando, FL, 2015.

3. Wilson, S.D., Wong, W.A., "NASA Glenn Research Center Support of the Advanced Stirling Radioisotope Generator Project," NASA/TM-2015-218462.

4. Thieme, L.G., Qui, S., and White, M.A., "Technology Development for a Stirling Radioisotope Power System," NASA/TM-2000-209791.

5. Dugala, G.M., et al., "Small Radioisotope Power System Testing at NASA Glenn Research Center," Proceedings of the Eleventh International Energy Conversion Engineering Conference, AIAA, San Jose, CA, 2013.

6. Dugala, G.M., Taylor, L.M., et al., "Advanced Stirling Convertor Dual Convertor Controller Testing at NASA Glenn Research Center in the Radioisotope Power Systems System Integration Laboratory," Proceedings of the Thirteenth International Energy Conversion Engineering Conference, AIAA, Orlando, FL, 2015. 


